\title{
Leaf waxes in dominant vegetation and soils in two forest ecosystem of the South American temperate forest
}

\author{
CAROL CERDA-PEÑ ${ }^{1}$, SERGIO CONTRERAS ${ }^{1}$, WESLEY \\ SCOTT $^{2}$ AND JOSEF WERNE ${ }^{2}$ \\ ${ }^{1}$ Universidad Católica de la Santísima Concepción \\ ${ }^{2}$ University of Pittsburgh \\ Presenting Author: carolpecer@gmail.com
}

Plant lipid biomarkers like leaf waxes have been used as vegetation and temperature indicators in soils. However, recent research suggests that regional instead of global characterization is needed because local environmental conditions might affect the preservation of these lipids. In the South American temperate forest (SATF) the leaf wax knowledge in soils is lacking, but it is expected that leaf waxes contained in soils would reflect similar patterns to vegetation due to the high biomass input into soils and low organic matter remineralization that favors the preservation of these lipids. The goal of this study is to compare the abundance and distribution of leaf waxes ( $n$-alkanoic acids and $n$-alkanes) between soils and dominant plants in two forest ecosystems of the SATF: Andean deciduous forest and evergreen forest. Soils and leaf samples were taken from six sites from each of the two forest types. The leaves of three individuals of the dominant species and two composite $(n=5)$ soil replicates were analyzed at each site. The lipids were extracted via Microwave Assisted Extraction (MAE) with Dichloromethane:methanol $(9: 1, v / v)$ and separated with solid phase extraction columns by polarity in different fractions. Long chain $n$-alkanes $\left(\geq \mathrm{C}_{25}\right)$ and $n$-alkanoic acids $\left(\geq \mathrm{C}_{24}\right)$ (leaf waxes) were quantified and identified using gas chromatography with flame ionization detection (GC-FID) and mass spectrometry (GC-MSD), respectively. The soil abundance of leaf waxes was different in the two forest ecosystems, probably due to differences in plant communities inhabiting the soils forests, however the two areas have a greater abundance of $n$-alkanoic acids than $n$-alkanes. The community of dominant plants in the two forest types also have a greater abundance of $n$-alkanoic acids than $n$-alkanes and within the evergreen forest, this difference is even higher between the two leaf waxes. In addition, the distribution index values on $n$ alkanoic acids are greater in the evergreen forest than in the deciduous forest. The results from leaves will be compared with those measured in surface soils, discussing different environmental conditions within the areas of study, types of vegetation and soils attributed to the SATF wide latitudinal extension. 